\title{
Machine made lace, the spaces of skilled practices and the paradoxes of contemporary craft production
}

“We're part of the machine. The machine can't work without us. There's a connection there. It's not like you just push a button and stand back."1

So says a skilled factory worker who has spent the last 50 years of his life in the machine lace industry in the East Midlands. The quotation reveals the strong connection between machine and operator, as well as between the operators who collectively produce lace - 'us'. It is a statement by a male lace maker, which both indicates some of the dynamics of lace production as well as the gendering of skilled labour in factory work. The quotation presents work as the product of various and differentiated labours, and implies something of the ways individual knowledge is translated into operational practice. Alongside the personal space of the individual looking, feeling and 'working it out' with the materials to hand, the 'we' of the machine suggests interpersonal spaces of collaboration and competition in production. The necessary human involvement in a mechanized process that the quote suggests also indicates that mechanization has not led to a deskilling of practice, but to alternate ways in which skill is manifest

Whereas research on the cultural geographies of making has tended to focus on artisanal skills and work places ${ }^{2}$, in this article we look beyond these niche settings to manufacturing skills in a factory setting. While a factory may seem a counter-intuitive place for insights into skilled practice or craft, we shall show that it has some relationship to the settings where Gibson argues 'workers once employed in factories mass-producing goods have [latterly] gained renewed agency as rare, skilled artisans in a craft-based mode of creative production'3. Further, following feminist economic geographers, we argue for an expanded and detailed analysis of relatively neglected everyday, embodied work, overlooked in 'a focus on immaterial, high-status employment in knowledgebased economies'4.

Our discussion of skilled practice is neither focused on 'knowledge work' nor on artisan production by isolated individuals. We are attending to the skilled work of individuals working together at the last remaining Leavers Lace factory in England, considering in particular the material and immaterial conditions that have enabled the factory to remain viable against a backdrop of globalisation. Following work in cultural and economic geography that focuses on the micro ${ }^{5}$ and on the processes of labour in production ${ }^{6}$ that are often hidden in macro analysis, we argue that inspecting the factory makes evident a series of paradoxes. We structure our discussion of the skilled work in the factory round these paradoxes, which seem to characterize the concentration and distribution of skill, knowledge and material resources in it. We bring to our discussion of the paradoxes a combination of frames that are influential on our respective 
backgrounds in Design and Material Culture Anthropology, recognizing that our work builds on studies of the characteristics of craft skill and knowledge?

The first of the paradoxes relates to the clear re-concentration of material and immaterial resources (human skills) in the factory, both in spite of and as a result of the global restructuring of the textile industry. While the first paradox relates to business organization and the actions of the company's management, the second concerns the skilled actions of the workers, and the way that their knowledge is both carried in their bodies, and is situated activity, beyond their bodies - enacted through the relationality of person, machine, document/ notation and factory space. Finally, a generalized notion of skilled practice in the factory, treating the factory as a single social entity, glosses over the consequences of the distinctions that exist between the people within it. Some of the workers have come from different factories, bringing habits, standards and assumptions, which together with an unequal distribution of opportunities within the factory, makes for distinctive work practices and outputs.

Thus while the factory like its output, lace fabric, appears to be a relatively homogenous entity, studying the skill and knowledge that go into what the workers call 'making production' brings into relief paradoxical relationships which can be set against the globalization of the textile industry, and in some respects derive from it. In its attention to the micro level of production at Cluny Lace, this article offers insights into the relationship of immaterial and material resources in what appears to be simply 'factory work' but is in many ways more akin to contemporary craft production.

\section{Background and Methods}

This article is based on ethnographic research conducted in 2013 at Cluny Lace, the last remaining factory in England making lace to use the process developed by John Leavers in Nottingham in the early $19^{\text {th }}$ century. Cluny Lace is located in Ilkeston, Derbyshire, in a region that was a nexus of lace production. The ethnography was part of the project, 'Nottingham lace: Capturing knowledge in people, machine and documents'8, funded by the UK's AHRC/EPSRC 'Science and Heritage' programme, located in Nottingham Trent University's School of Art and Design. Recognizing the insecurity of the machine lace industry in England, the research was motivated by a need to understand the skills and knowledge specific to Leavers lace making process before these insights were dispersed too far outside the factory to effectively re-capture ${ }^{9}$. It also wished to address in the personal, social, material and environmental relationships between the workers, the machinery and their communities of practice ${ }^{10}$.

Leavers lacemaking is a mechanical process, originating c. 1808 in Nottingham to mimic the hand making process. It does this by mechanically twisting two sets of threads to create net structures, with a jacquard mechanism that modifies the twists to create lace patterns. The technology stabilized and ceased to develop 
further after the late $19^{\text {th }}$ century, and in the mid-20th century, it was overtaken by a mechanized lace knitting (rather than twisting) process, called Raschel, which could deliver higher output with fewer workers. Although Raschel is more automated, and more efficient, conforming to the 'efficiency, adaptability and flexibility'11, of modern production, its product lost the 'hand made' character that Leavers retains. This technological development of Raschel machine-making processes coincided with the shift of much lace production to China and SouthEast Asia in the $1980 \mathrm{~s}^{12}$.

Cluny Lace has been manufacturing Leavers lace since $1845^{13}$. It is 'owned and managed by the eighth and ninth generations of the Mason family in textiles'14 and since 2005 has dedicated itself exclusively to the production of Leavers Lace. Recognising the shift in industry in 1999, ninth generation managing director, Charles Mason, took the decision to sell off their Raschel lace machinery while they could still get a decent price for it 15 , and begin to focus entirely on Leavers Lace. Whereas they could not compete on price for Raschel lace made overseas, rather than participate in a 'race to the bottom' (Gibson, 2016: 75) by becoming more automated, faster, and therefore cheaper, they could create a niche market for themselves as producers of a traditional lace, emphasising 'high-cost materials, rare labor techniques [...], and design intensity'16. Instead of a wide appeal to mass markets, Cluny Lace shifted its business model to trade on authenticity and heritage. It 'maintains its place, albeit precariously in the global marketplace, by marketing its lace for elite buyers, with recent notable commissions for Catherine, the Duchess of Cambridge's wedding dress in 2011, and for inclusion in Burberry's collections from 2013'17. That Cluny Lace focuses on this anachronistic production process, and survives by doing so, indicates the 'higher value'18 added by concentrating on the distinctive Leavers product, with its skill-specific qualities.

Granted access by the Charles Mason to the factory during working hours, the research operated on the principle that work-based skill is best understood when the actual work is being undertaken ${ }^{19}$ - the factory is a 'pivotal' setting for the research ${ }^{20}$. Insights were informed by design research, which inspects human-material interactions in relation to work and everyday experiences, as well as textile craft practice, with particular reference to embodied skill ${ }^{21}$, taking a relational and practice-orientated view of the material interactions it comprises. Insights were also informed by material culture and visual anthropology, with an attention to the doing of making ${ }^{22}$ and its representation.

Participant observation was employed as the interpretative method to understand the distinctive ways that skills, knowledge and practice play out in the factory in conjunction with the material components of production. 'Attending'23 to the workers as they undertook their roles enabled the relationship between the researcher and participants to develop sufficiently to produce an understanding about their work and the place of skilled labour at the 
factory. In the five months of data collection (from March to August 2013), Botticello became a familiar, and trusted figure in the factory. Methods included talking to workers as they worked, observing what they did, taking part in work processes, recording the dialogues, as well as using photography and film to document and unravel the complex human-material (and human-human) connections involved in making ${ }^{24}$. The level of trust she achieved meant she was able to engage with some of the processes, having experiences that formed a measure against which she could begin to assess the skills involved. It also meant that through casual discussions that arose, she was able to learn from the workers' experiences and views more about the trajectory of the region, and the global industry in which the factory is placed. .

This process of situated and discursive fieldwork revealed how the spaces of skilled practice at Cluny Lace incorporate a number of elements. These include locations salient to the lace workers beyond the factory setting itself - their place in the work flow and the work-place hierarchy to the wider industry. The range of salient material elements includes the workers' tools, patterns and charts, as well as previously made lace samples. The efforts of former lace workers are also evident in less formal ways that are necessary to the workers' actions in the present. These took the form of tools, notes and inscriptions, some on the machines themselves. Finally, the wider materiality of the factory, as a historical space housing specific machinery for Leavers lace manufacture comprises the container for all these elements. Although each piece of lace produced is a complete and discrete entity, it is, in effect, the sum of inputs from these multiple elements, which have been brought into the present through the retention and resurrection of material and immaterial legacies in this historic place and region of machine lace production in England.

\section{Critical context}

Although the current state of the UK lace manufacturing has a root cause in the same forces of economic globalization that Gibson discusses ${ }^{25}$ - a change in quality expectations and price together with cheaper production costs - we do not present here a history of demise of the industry. The bare facts are left to speak for themselves, and this history remains to be written. In some respects, the closest antecedents of what we present are in studies such as Terkel's 'Working'26, which presents direct worker testimony from interviews, and Beynon's ${ }^{27}$ and Glucksman/Cavendish's ${ }^{28}$ factory research in the 1970 s and 80 s. We do, however, attend to how the consequences of economic globalization have impacted on practices at Cluny Lace, as a factory and for the individuals and groups of workers within it. Following Jones and Murphy, who state that a focus on the 'everyday micro-social practices influence[s] and embod[ies] the complexities, contingencies and meanings that constitute most socio-economic and political economic phenomena' ${ }^{29}$, such a perspective provides satisfactory context about the wider picture in which the particular, geographically 
embedded production processes take place.

In addressing the assumption that modern production leads to the demise of skill - what Braverman called the 'destruction of craftsmanship' 30 - we argue that the material interactions in skilled factory production do not constitute craftsmanship 'emptied of its traditional content', as Braverman suggests, but are rich new 'hand technologies' and 'creative work' as Samuel ${ }^{31}$ and Gibson ${ }^{32}$ argue, respectively. Ingold identifies a tendency in technology to 'capture' the skills of crafts people ${ }^{33}$, leaving them bereft in the process. Although the Leavers loom was designed as a technology to replace hand work, rather than obliterating skill, the industrial craft workers adopted new ones, engaging with the vagaries of the machinery as part of their own, rich, practice.

Gibson highlights that the material dimensions of craft knowledge need to be understood within labour processes, while Jones and Murphy see these 'entire situations' as communities of practice, in which the focus is on the communication and transfer of learning, know-how, skill and processes of innovation ${ }^{34}$. Taken together, these elements are suggestive of the chaîne opératoire approach, used to explain skilled processes and surrounding contexts. This approach, which refers, on the one hand, to pathways of action, or operational sequences, also takes into account how these sequences are embedded within, and susceptible to, material and social frameworks. As Schlanger states, 'approaching technical activities in practice, as they unfolded, could show how they are at each moment materially determined and also socially mediated'35. Attention to materials and practices are both needed to begin to understand the concentration of skill within the factory as well as its distribution across it.

Skill exists as relational practice, between the head and hands of a particular worker and wider social, material and geographical spheres in which he or she is embedded. Mechanization does not necessarily result in the deskilling of a workforce and technology does not 'augur the end of skill' 36 , but brings into being both different skills and differential levels of skill. Consideration of practice as both communication and skill manifestation leads naturally to the principle of relationality37, where skill and 'know-how' are distributed across individuals, organizations, objects and particular spaces. This resonates with activity theory, which also emphasises processes and relationships over singular products or persons. As Lave writes, “"cognition” observed in 'everyday practice is stretched over, not divided among mind, body and culturally organized settings (which include other actors)' 38 ,. Star also underlines the point that know-how and skill are situational, and that 'understanding is both dynamic and local' where locality is 'an entire situation of activities and material conditions - bodies, other people, machines, as well as documents, formal organizational arrangements and previous interactions', and the dynamism involved arises from the 'coimplication' of each of these in one another ${ }^{39}$. 
Locality is also place specific and is of particular significance in terms of the latent potentials in sites of historic manufacturing. As Gibson states, 'industrial legacies resonate [...] in the urban built fabric as well as in the tacit knowledge possessed by surviving workers' 40 . To only focus on the mutual making of persons, in places, with materials, however, does not sufficiently contextualise production and conflicts over skill. As Herod et al argue regarding work and employment practices, 'economic life has experienced a dramatic rescaling' 41 through various processes, including 'recentralization' 42 , as discussed here. Problematizing the notion that scale only manifests in broad contrasts, such as those between the local, national and global, Herod et al argue instead that attention to scale reveals networked connections through and across these broad demarcations ${ }^{43}$, suggesting that scale is a social product. Connected to differing lineages of production, the reconcentration of workers in this one factory reveals their ongoing networks of connections elsewhere which is played out in their work practice. The singular term, 'local' does not capture these differences. In a context of competitive production decline, tacit knowledge, while locally evident, is multiple and engenders various communities of (potentially conflicting) practices.

The correspondence between the constituent elements of these multiple communities of practice, their material affordances and geographical emplacements are essential to understanding skill, know-how, and their differentiation within Cluny Lace as well as how these situate and are situated by Cluny Lace as an economic entity within the macro field of global lace production. It is to these concentrations and distributions that this article now turns.

\section{Situating: the factory, its contents and connections}

This section explores the first of the paradoxes identified earlier, concerning the continued existence of Cluny Lace and the re-concentration of material and immaterial resources in its factory, both in spite of and as a result of global redistribution of the industry as a whole. Initially, the research sought to understand the different spaces of the factory in terms of sites of processes and how these related to work, materials and people. This entailed a rough mapping of different spaces of the factory, what machinery was housed where and how the spaces and machines related to the internal flow of production. Naively, we assumed we'd find a relatively stable entity, with work, people and materials in fixed relationships to the factory and to lace production; in effect a 'working museum' 44 , reproducing itself through repetitious actions in a historic site. The situation is more complex.

One building on the Cluny site dates from Victorian times; this is a three-storey construction of red brick, with high paned windows and wooden floors. When the machines are working, it sways slightly in response to their heartbeat-like 
rhythms, 'grasping' 45 workers and visitors alike. It houses 'greige' (or grey) lace, just off the machine, in its attic, waiting for transport to Calais for dyeing and finishing, before returning to the factory for reeling onto cards. The 'brasswinding' area is the third floor, where the nylon threads from Italy are loaded onto the thousands of brass bobbins that go with each machine. These form the inner threads around which the Egyptian cotton 'beam' yarns are twisted in the lace machines. The other floors in this building house more Leavers machines, some working, some in the processes of restoration.

Other parts of the factory complex are single-storied and were built in the second half of the $20^{\text {th }}$ century to house the Raschel knitting machines. Since the sale of this machinery from $1999^{46}$, these spaces now house the nylon thread spinning machine (from Italy) and a number of more recently acquired Leavers machines, originally made in Nottingham but dispersed across the local area and Europe in the heyday of production. These have been bought from now defunct firms and put into use, re-collecting an industrial and material heritage in the one site. A story from a mechanic who keeps the machines in good repair shows the knowledge potential that is embedded in the machines. When lace was a flourishing local industry and competition was rife, a factory that needed to get rid of an old machine might not sell it, but smash it ${ }^{47}$. These material aspects of intellectual property were as valuable as the workers who could run them.

Leavers lace machinery is not the only acquisition Cluny Lace has made from failing factories. On several occasions Botticello was told about how the firm has also acquired jacquard cards, drafts and figure sheets for other designs of lace, adding to its knowledge resource and its intellectual property ${ }^{48}$. Personal notes made by former twisthands - the lace makers who run the Leavers machines about which threads need moving in changing from one pattern to another, were also inherited; these can be used to recreate draft sheets, the basis for setting up machines with a particular lace pattern. Cluny lace has added these more ephemeral remnants of the work of (likely deceased) competitors' employees to its knowledge capital, along with machines and patterns.

Cluny Lace also acquired human capital - workers have joined the company from other firms. The brass winder, who used to work for a competitor factory, details this process during the liquidation of the firm Guy Birkin, registering the relative mobility of both human and material capital.

It's like when Birkin's was shutting down. We knew come the January, the majority of the staff would be gone and the only ones left were the few on the Raschel side clearing everything out, [as] most of the machines would go to China. And us handful [on] Leavers side left to finish off what orders we'd got. We only had PS and LH left as twisthands anyway by then, and IP was on the Raschel side, but he [would] come in and out, 
helping'49.

Each of the people mentioned here, PS, LH, IP and the brass winder herself, JS, had come to Cluny Lace on the demise of its competitor, Birkin. This inheritance of the material required to make designs includes the movement of workers, alongside machinery, patterns, figure sheet, jacquard cards. It is both part of a process of knowledge dispersal on the one hand and knowledge concentration on the other. Some of the material and immaterial knowledge, and the skill dispersed by the globalisation of the industry have been contained in this one factory.

It may seem unremarkable that Cluny Lace acquired the remains of factories as they went out of business in the global shift from domestic to off-shore production. However, in the interface between materials, knowledge, and the capacity to produce, the materials hold a knowledge and skill potential, which in the right hands (literally) can be translated into output. This set of relationships is clearly a case of the 'deep and considered relationship with materials' on which Carr and Gibson base their critique of the binary between 'craft' and 'manufacturing'50 and positions the work of Cluny Lace clearly in the 'craft' category. It is only with the addition of human skill that these potentials can be realized in the production of lace patterns that increase its product range. Jones and Murphy call this structural power, useful for understanding 'power relations and their complex variations within the space economy'51, as this one factory in East Midlands, literally accumulates the (predominantly) local capacity to compete more effectively against any remaining or potential competitors, in what Gibson refers to as 'place-specific inheritances'52.

This aspect of the 'sociospatial dynamics of industrial organization'53, has concentrated a set of worker skill and production materials previously distributed across the East Midlands into a single factory, offering a scaled down version of the shifts in lace production globally, in terns of both concentration and dispersal. Dispersal and concentration are seen both in persons, in that some current Cluny Lace workers have worked in China and elsewhere, and in machinery - there were 2,600 machines working in the Nottingham region in 1900 , now there are only the 16, all of which can be found at Cluny Lace. The factory and its contents reflect an ongoing dynamic of 'networks' and 'connections'54 between local and distant production activities.

While the factory site expanded in response to modern technological changes; these same spaces have seen been repurposed in response to changes in the firm's business model, and in the Mason's family's abilities to acquire and house materials and machinery from closing factories - one worker commented that 'Charles owns half of Ilkeston'55. So whereas historical ebbs and flows of scale and location mean the industry is now globally distributed, in the case of this factory, the reverse is the case. In the face of global shifts in textile production, 
Cluny Lace has managed to survive and benefit, siphoning in remaining human and material resources from the local lace industry as its competitors collapsed. In a parallel of Gibson's story of the bootmaking industry in El Paso where 'the region contained the largest pool of [...] skills and had deeply embedded social networks and regional cultural traditions to feed it'56, Cluny Lace has also been able to draw on extant material and immaterial resources in its local region to survive.

\section{Situating workers' embodied knowledge}

A desire to understand where knowledge is located - in people, machines and documents - reflects the original purpose of the research and led us to trace these locations in Cluny Lace's working environments. Here, the knowledge in people exists in the skilled workers with their embodied knowing built up over a lifetime of practice. Grasping the knowledge in machines meant getting an understanding of how the lace machine works. The complexity of its vast numbers of threads moving from side-to-side and back-and-forth twisting around one another, does not make it easy to understand how it is set up, or kept running. The work meant accessing formal documentation of histories and process 57 , alongside publications by the employers' federation ${ }^{58}$, through which empirical evidence in the machinery could be understood as well as recent work on the economic and social history of the industry ${ }^{59}$.

While it is clear that different types of knowledge reside in these different places, the paradox we wish to explore here, is that knowledge is not only embodied in worker's bodies and minds, manifest in their actions and gestures, but also exists in machines, and in certain types of documents, particularly relatively informal ones that are closely linked to their everyday negotiations with the machinery. Knowledge embodied in such documents, and inscribed on the machines themselves is part of the situated activity, the workers' 'distributed mind'60, where machinery, materials and documentation form extensions of their embodied faculties. The workers used the machinery as a specific site for notation, making it part of their own informal documentation, as a way to complement knowledge held in the body and locate it in their environment.

We will first review some established ways to understand embodied knowing in people. Following Sennett, this is seen as the thoughtful collaboration between doing and thinking, routinized through repetitive action and formal training. As Sennett states, 'every good craftsman conducts a dialogue between concrete practices and thinking' 61 , where acquired knowledge is ultimately carried in the head, appraised through the senses (mainly, though not exclusively vision) and manifest in hands and gestures. This approach to tacit knowing is derived from Ryle's ${ }^{62}$ integration of mind and body in the process of knowing, detailed in the contrast between 'knowing that' (reasoned, mental knowledge) and 'knowing how' (practical, applied knowledge), where documentation tends to inform the 
former and participative action informs the latter. Our recognition of embodiment in persons builds on these perspectives, drawing from Ingold's study of craft in anthropology 63 , Schon's attention to reflective practice ${ }^{64}$, and 'chaine operatoire' approaches 65 , which combine the material and the social. This means we observe the setting of the factory, and its material and human components not as 'the operation of a technology, but as an instance of skilled practice', as Ingold puts it. 66

The nature of that skilled practice became evident at certain moments, for instance when there is a large order on at the factory. Then, some of the people whose work isn't urgent to the running of the machine will work together to thread the bobbins into the carriages, to keep pace with the machine's consumption of thread (Figures 1a and 1b). Many people can do this job learning to thread would be one of the first jobs you would do in the lace trade so it is a skill everyone has, though it is by no means easy. As FM, once employed on the Raschel machines put it, as a child he would come down to the factory 'after school and holidays, [to] do a bit of threading'67. The depth with which the skill of threading is embedded in the workers was emphasised by a comment by DG, the factory foreman that when FM is threading he will appear to be asleep, with his eyes closed 68 . This demonstration of what DG calls 'muscle memory' emphasizes that threading is not a visual skill but a felt one, embodied in the muscles. The fact that DG, the foreman, will turn his hand to threading when needs be, emphasizes that automatic though it may be this skill is part of a skilled practice, part of the factory setting.

While muscle memory is prominent in some tasks, more often than not, workers have to think through their work in order to do it. The machinery is never less than 70 years old and part of a technology that 'matured' some time in the second half of the nineteenth century, so it constantly throws up new challenges, in addition to the inherent complexity involved in machine lace making. This means that a good deal of dynamic reflection in action ${ }^{69}$ is required if the workers are to get acceptable results at all stages of the process. This is particularly around setting the patterns on the machines (Figure 1c), managing thread tensions, fault finding when something goes wrong with the process and mending the lace once it is removed from the machine.

Here two twisthands comment on this process of fault-finding, or problem solving, as we came to understand it:

You can only learn through experience, through actually being on it and trying different things and saying "ahh, that works". But that might not work in another machine. So you have to weigh up the pros and cons, try different things. ${ }^{70}$

I am in charge. If anything goes wrong, I've got to be able to fix it. If I can't fix it, then it's something very serious. I can fix anything at the moment, 
because I've been trained to. I've seen all the obstacles all through my working life of what can happen to a machine, and it stays in your head. Knowledge. That's what I think anyway. ${ }^{71}$

Although two twisthands here express their know-how differently, both quotations suggest that it is experience that builds their knowledge base giving them the ability to find and fix problems.

Problem solving might appear to be a process of consulting a 'knowledge bank' built over years of experience, yet it is nonetheless embodied knowledge, the active form of knowing that Malafouris characterises as the basis of our creative endeavours, which are 'temporally emergent and dynamic products of situated activity,'72. The twisthands may bring skills and competencies gained over a lifetime of practice to each task, yet they are always brought to bear on the unique challenge confronting them. As the second twisthand quoted above put it, speaking about this aspect of his practice, 'it's been a life-time of everything new. Every time you alter a pattern, it's new. It's like a new drawing, you turn the page, haven't done that before, see what I mean.'73 So while the embodied knowledge of the twisthand incorporates somatic memory, which can operate through seemingly unconscious action, it also entails a more dynamic and conscious process of thinking through what's in front of you, and the ability to make judgments and decisions based on a repository of resources that includes both reasoning and embodied skill. This aspect of the twisthand's work is not repetitive, as being reflective practitioners ${ }^{74}$; they are always applying their know-how to the complex problems production throws at them.

This brings us to the second half of the section, which explores the paradox that embodied knowledge not only resides in persons, but is also distributed materially into the work environment. Cluny Lace workers consciously note and mark their environments to 'disembody' knowledge, to be understood later by themselves or others. As mentioned earlier, twisthands make personal notes about how to change from one pattern to another on a machine. Even though the twisthand carries much embodied knowledge, he also uses these external referents to enable him to carry out his work more effectively. Pattern changes occur frequently, so working out what is required to change from pattern number 109 to pattern number 250, for example, saves having to work it out from scratch each time. Twisthand PS keeps a reporter's notebook of pattern changes (Figure 2a) by his workspace, recording how he needs to change the components to make the machine set up move from one pattern to another. He records the minimum number of changes needed to alter the thread positions already in the machine to create the new pattern. Although this information could be shared with other twisthands, as it is specific to the pattern and the size of the machine running it, Botticello never witnessed such sharing. This emphasizes the personal nature of these notes, as they are for making one person's production processes more streamlined. Keeping such knowledge 
private may have had a financial incentive in the past when workers were paid on piece work, by their output, as it would have helped to speed up their individual production.

Disembodying knowledge in this way means it need not be recalled, or worked out, every time, but can simply be looked up and applied. This points towards the distributed cognition that Malafouris traces to the earliest uses of writing in Mesopotamia, which leads him to the observation that 'material culture is potentially co-extensive and consubstantial with mind 75 . In this case, reading the 'material' transcribed away from the machine is more effective than reading the machine itself. There remains a potential for knowledge embedded in nonhumans to be put to new use, as mentioned earlier in the smashing of old machinery, so that competitors could not use it, and as we noted above, previous twisthands' notes on pattern changes can put other skilled practitioners in a position to work back from the notes to create missing information.

As recorded in Botticello's fieldnotes:

[Foreman] DG sat down to try and work out the figure sheet for a pattern that's not been run for a while - possibly ever by Cluny. He was there ready to draft a new figure sheet, and was trying to create a dead stop for the pattern (which is what the figure sheet represents) and all he had to go on to create pattern 307 was the pattern changing sheets from previous, and in all likelihood dead, twisthands. There is a pile of these upstairs in Charles's archive, and DG went through to try and find anything that had a pattern change to or from 307, as this might give him clues as to what the dead stop - absolute bottom basic and the lowest thread position for one breadth of the pattern - would be. He said he enjoys this work, like detective work, trying to find out the dead stop though this exploration ${ }^{76}$.

Some of these earlier 'cheat sheets' were written on waxed brown paper and were saved, not for their beauty, but their utility (Figure 2b). Whereas they had personal utility when first created to save time and maximise income, because the skills to interpret them remain in another practitioner, and the production technology is relatively unchanged, these notes make it possible to resurrect a 'lost' pattern, which Cluny Lace, inheritor of material and immaterial intellectual property, can now make.

In addition to making paper documentation, twisthands also mark the machine itself and many of the machines have this 'dead stop', the beginning point for the pattern, permanently scored into it by previous twisthands. One could see this 'marking' as a scaling up, and making share-able what many individual craftspeople will do in their ongoing negotiation/engagement with material. In all but the most fluid and dynamic craft processes (e.g. glass blowing77) stable, lasting marks are possible, and are made routinely. This is not 'marking out' (i.e. 
drawing what to do on the workpiece before you do it) but is the process of marking the equipment, a bench, a tool, or a machine, to make repeated operations easier. Like other notations, the deadstop mark serves as a personal 'aide memoire' to further help the twisthand recognize the relationship between the computational aspects of the pattern (recorded as lists of numbers on figure sheets) and the physical arrangement of the threads in the machine.

There were alternative inflections to what seems to be the sharing of knowledge by disembedding it from the machinery. When confronted with a machine and components already scored with others' markings, one twisthand chose to overwrite these with his own versions. Although the machine had a dead stop location engraved in it by a previous twisthand, this later twisthand decided to mark a different breadth as the dead stop and made his own marking as a white permanent marker line on the machine. He related this dead stop 'breadth' (the section on the machine that forms the repeated unit in the repeating pattern), to other machine components by marking the carriage edges behind which the breadth threads lie (Figure $2 \mathrm{c}$ ). Although adding these semi-permanent markings could be framed as rejecting previous twisthands' work, they may be understood as part of a shared practice of adding information to the material resources of the factory. The marks on the machine therefore not only embody his working knowledge, holding information that would otherwise be too complex to 'bear in mind', but are also a materialization of this continuity of practice.

Such rich insight into the workers' informal documentation reveals systematic skill and know-how evident outside the body, which can only be read and understood by others sharing the same practical competence. This points towards the distribution of skill within the factory, suggesting a material turn that 'twists in numerous directions'78 from intentionality to emplaced action, where 'everyday practices are "time-space assemblages" of minds, things, knowledge, discourse, and structures'79, suggestive of Gell's ${ }^{80}$ distributed mind traversing times and spaces. It also relates to the implications of such 'aides memoire' to recent insights from discussions of cognition that are germane to design ${ }^{81}$ and to understanding skilled practice. Knowing is 'inseparable from everyday life and practice' 82 and tacit understandings are 'often only realized in the "doing" of business'83 and in people, materials and machinery, or their legacies. Skill is the embodied, practice-based articulation of such knowledge and as seen here, it resides in people and materials, able to be re-employed in other places and at other times.

\section{Differentiating in practice and skill}

The third and final paradox this article wishes to articulate is that a generalized notion of 'skilled practice' glosses over an unequal distribution of opportunities 
within the industry traditionally and as a result of the reconcentration of various skilled workers into producing Leavers lace at Cluny. This reconcentration, however, does not translate into a uniformity of 'Cluny Lace' production practices; rather workers retain parallel and distinctive work practices and knowledge sets ${ }^{84}$ allied to their original training bases.

From a production perspective, the movements of materials around the factory point directly to the co-implication of others in an individual's activity that Star identified in her consideration of skilled work. The different elements of the process are more and less mobile in the space of the buildings. The threaders, who place the nylon-wound bobbins into the carriages, ready for loading into the machine; the beamers, who wind the cotton yarns onto beams (Figure 3a); and the twisthands, who undertake all loading, running, and fault finding activity on the lace machines themselves, all move from one work location to another, as necessary.

The nature of the winding process and the equipment it needs, however, means the brass winder herself is fixed - it is the bobbins she fills that move instead (Figure 3b). The machines also are fixed, the bobbin carriages staying with their machines and the bobbins moving to and from the brass winding station (Figure 3c) before being loaded into the machine. There is a hierarchy inscribed in this material flow, centring on the twisthand, which implies that there is also a hierarchy of skills.

Threading is the lowest-status skill in the production process, and as mentioned previously, is likely learned first. As the brass winder admits, 'a small child could easily sit there and do it successfully' ${ }^{\prime 2}$. Beaming, which is winding cotton yarn onto long beams ready for twisting around the threads, is more skilled, in that one has to manage many threads at once. While it is a different process, beaming is similar to brass winding in that respect. Brass winding loads threads into the bobbins, which the threader can then place into carriages. Bringing the filled carriages together on the machine is the role of the twisthands, in whose work all mechanized aspects of Leavers lace production coalesce.

The opportunity to advance from threading to other more skilled work has historically been dependent upon gender, but also potentially in response to the needs of the firm in the context of the evolution of the industry. Regarding the former, JS recalls the dismay she faced while at Birkin when working on a lace machine.

The first time I went on a Raschel warp [...] all the men kept coming around and looking. [...] They've never seen a woman on a warp before, just tying it in 86 .

Although she did manage to work on both Raschel and Leavers machines, training to be a twisthand was her ambition. As she says, 'I wanted to be a twist hand as well, but they wouldn't let me. I would love to have run a machine. 
Birkins (sic) would never let a woman on a machine. I used to want to. Never been given the opportunity' 87 .

She elaborated that the traditional gendered division of labour tended to limit women to threading, brass winding - her role - and mending. A forward-thinking factory, Cluny had previously trained a woman to be a twisthand, and since 2015, she has been back on site working in that role 88 . Due to the length of time to train in skilled work, once one became established in a particular role, that role tended to stick.

In regard to the latter, the relationship of individual potential and industrial demand, we return to FM. Here he charts his training as shifting from Leavers to Raschel, the outcome of which has left him underskilled in an industry that shifted in the other direction.

I started in Leavers and all Leavers started closing down. Raschel started taking off everywhere so I went into warping. I still did a few for Leavers. [...] I were training to be a twisthand, for 6, 7 months, then one of the warpers left. They said everything's going to go to Raschel now, all this side's going to be finishing up, Leavers, and then it were the other way. Rachel finished and Leavers is still around 89 .

For FM, his opportunity to use and develop his skills shrank when Cluny returned to a Leavers only production base. MJ, also from the Raschel side, however, was given the opportunity to train as a twisthand and has been doing this successfully for over 10 years. Speaking to the brass winder about why one but not the other, she replied that it is 'because he's a good worker. [...] Especially for the likes of Charles, that does go a long way, being a capable worker'90. The scaling down of the industry meant that there were many human resource casualties, where fiercer competition among workers meant that those who had less potential were not progressed, while others with more potential were able to thrive in the new situation. This includes employing women in traditional men's roles. As Gough argues, these occurrences draw attention to 'the material processes of production, the allocation of workers to production tasks, the control of workers by management in these tasks, and-crucially-the interrelations between these' 91 . The vignettes above demonstrate that the development of potential skill, skill re-allocation by management, and the need to constrain/maintain their workforce operate in response to both the local and the wider social and economic situation of the industry.

Moving into the second point, about how the reconcentration of skilled workers into one setting does not create a homogeneous work environment, we now focus on twisthands. This is the person who sets up a pattern on the machine, checks tensions on yarns and threads before tying them into the machine, and tends to its running. In this role is the coming together of the materials supplied by others to make lace. However, the real skill is not in assembling all these on 
the machine, but in problem solving once the components are there and something goes wrong.

Commenting on this work, one twisthand offers that:

Most people, anybody could probably watch a machine and make production, but it's when the machine stops, that's when the twisthand comes to his own. And it's only through many years of experience and looking at the different faults that one can pick up, that you can actually fault find and solve these problems. It takes a long while because there are so many different reasons why one thing can go wrong. There are so many ways of putting it right. It is not always clear and concise ${ }^{92}$.

In being able to find faults and correct them, the twisthand sets himself apart from his colleagues and this refers back to the build up of embodied knowledge over the course of a lifetime of work discussed earlier. One twisthand revealed that 'all twisthands are jealous of one another'93. It is this sense that an individual has of being able to do the work and do it well, which suggests a hierarchy of skill within the same roles and not just between the different levels.

While it has been commonplace for twisthands to be in competition with one another over skill, a particular dynamic at Cluny Lace brings this to the forefront more than usual. Cluny Lace has not only acquired the machines and documents from its unsuccessful competitors, but also some of their workers, which brings different practices and workshop methods into direct contact. As Reimer discusses with regard to the geographies of creative production, 'clustering and firm agglomeration' 94 tends to be about sharing knowledge and practice across increasingly 'porous firm boundaries' 95 . Further, as Gibson argues for the boot industry, 'such tacit cooperation underpins this distinctive craft-based form of network retention'96. At Cluny however, even while individuals operate under the same roof and in the same workshop space, their amalgamation from different firms has not created a space for know-how and skill exchange, but the condition for their strict demarcation.

Speaking about the way training has previously taken place at the Cluny Lace factory, the foreman commented:

When you worked here, you did everything yourself: that's pattern change, bar setting, weighting out [...] we have to do everything ourselves. That's why if you were trained here, you can work anywhere ${ }^{97}$.

A former Birkin employee reveals the situation on the shop floor from her perspective:

At Birkins (sic), there was a lot of help for the different jobs - there were 'shop floor lads' who assisted with tying in beams, putting in carriages, so that the twisthand just had to step up to the machine when it was ready to run. Now, here, the twisthand does all this preliminary work himself. ${ }^{98}$ 
In contrast to the Cluny-trained workers, who know all the processes from experience, the twisthands with a background at Birkin, having gone through Birkin's training programme ${ }^{99}$, feel themselves to have strongly standardised protocols for work, with particular ways of operating on the shop floor. It has been a change in practice for them to have to do everything themselves and while they are capable, there are residual grievances. One Birkin-trained twisthand mentioned what he feels to be bad practice among the Cluny-trained twisthands, that they don't manage their lace machines well. He spoke of two things in particular. One was wrapping up and tying a beam once it has come off the machine, so that it's neat and ready for the next twisthand. The other was about folding a jacquard pattern and tying it, ready for storage. To his mind, this brings a professionalism that perhaps Cluny never had and smacks of bad practice and rude behavior between twisthands; a disregard for the next person on the machine. Cluny workers, however, argue their case for being generalists, able to do every task, even if not following strict form, and so not bound by these conventions. This comes down to their particular training/education, which was to do everything themselves and not to rely on rules and protocols. While twisthands are unified in seeing themselves at the centre of production and consider their work as the most significant in the factory, at Cluny Lace, they are also a heterogeneous group of individuals, differentiated by the distinct workpractices, know-how and skill, who have been brought together by global production shifts and their local impacts.

These lineages of education play out, not necessarily in the material evidence of the lace that is made, but as technique and modus operandi. Citing Lemonnier, Schlanger offers that whereas some techniques are 'strategic acts', which cannot be altered, others are 'technical variants', the choice of which is 'arbitrary in material terms, but [is] nevertheless, socially and culturally relevant' 100 . Although there are particular sequences that cannot be altered in the lace making, such as carriages needing preparing and sorting before inserting in the machine, it matters precisely how this is done because this denotes where the worker was trained.

The qualities inherent in these different approaches do not manifest in the material; what does come out in the final product is the differentiation in skill, regardless of training style. In response to a question of who is the best twisthand, ST, the mender (who was trained neither at Birkin nor Cluny but another defunct competitor, Roper) named one (Cluny trained), then another (Birkin trained) twisthand. She commented that she would never praise their work, because twisthands are already over-inflated in their egos, so she always tells them that they're rubbish ${ }^{101}$. In fact, when an error does come through, she has no qualms about taking them to task over their carelessness, such as when a 10-meter error occurred.

Flaws reveal the connectedness of all aspects of production, as everyone's work 
is everyone's responsibility. Being situated at the end of Cluny's production line, and once the lace web is removed from the machine (Figure 4a), menders have a particular relationship to the skills of others, as they have to repair their mishaps. All mending at Cluny is done by hand, not on a machine. The large scale of the 10-metre error meant two women, the brass winder and the reeler, were seconded from other parts of the factory to assist in repairing the damage (Figure 4b). While engaged in the repair, the three menders bantered a bit, saying that the twisthand's wages should be docked and added to theirs for having to repair on his mishap. They also said that this particular twisthand wouldn't be showing his face in the mending room for some time ${ }^{102}$. They nevertheless got on with the work and focused on doing decent repairs in spite of the perceived injustice. They were very aware of the value of their work in this regard and which twisthand would be beholden to them for it. This demonstrates that the distribution of skill in the factory is not always of mutual positive value for individuals. However, this distribution is one of the ways of 'spreading the risk in occupations, [so] that different occupational groups share the blame, mistakes and risks'103. Although they are not on the factory floor, they are nevertheless aware not only which machine has made a particular piece, but also which twisthand has produced it, based on the skill evident in the physical piece of lace presented.

These discussions on the factory floor tended to focus on the immediate tensions between workers about their skills and practices. 30 years ago, this would not have happened, as the industry was flourishing and workers from competing factories would not have had the opportunity to work 'together'. Underlining these 'micro' discussions, then, are the reasons why these workers happen to be working within the same space: a shrinking industry in England, precipitated by the shift of production overseas, and British firms, like Marks and Spencer, commissioning lace from abroad instead of domestically. In defense of a relational geography, Bathelt argues that 'the relational perspective does not rule out macro-theoretical considerations, because human agency is not independent from the conditions of the capitalist system' ${ }^{\prime 104}$. While these discussions between workers may seem like common workplace tensions, they reflect the changing macro geographical space of production in the lace industry, and document its direct impact on their working conditions and practice on a micro level.

\section{Conclusions}

In this paper we have outlined some of the paradoxes surrounding contemporary factory-based craft production in England at Cuny Lace and how these contribute to its survival. These paradoxes have been articulated through attention to the distribution and concentration of both material and immaterial resources and the knowledge and skill potential in them.

Holding its ground amid the shift in production to China and the Far East, Cluny 
Lace has enhanced its capacity to produce lace by acquiring not only documentation and machinery from its former competitors, but also the skilled workers who can read and run these. This affirms Gibson's statements that, 'economic transformations emerge [...] through material relations, actors and socio-technical networks [...where] such aspects [...] become new geographies of craft production in a era of cultural capitalism where authenticity is the key source of value'105. The paradox here is that by actively acquiring what others were selling off and disposing of, Cluny was enhancing its capacity for survival.

The second paradox concerned knowledge and skill and the location of their embodiment. As we argued, although the embodiment of knowledge in persons has been closely considered, less attention is given to its distribution in the material environment. The validity of Malafouris' assertion that we need no longer 'reduce the complexity of an extended and distributed cognitive system to the isolated brain of a delimited human agent'106 is evident in the relationships between people and human others, between people and machines, between people and documents. Our examples reveal that due to the relative consistency in Leavers lace technology, the mind of a worker from 50 years ago can connect to that of a Cluny worker in 2013, sharing knowledge through material means. This takes Jones and Murphy's relationality, as a 'product of collectively legitimated (everyday) social practices wherein and through which knowledge [and skill are] embedded'107, to a new level which transcends both time and space, crossing boundaries unable to have been traversed in the intense competition of lace production in the East Midlands at its height.

Finally, attention to skills and their development amid 'fragmentation, centralization or dispersal'108 is juxtaposed against ongoing competition in the factory among the remaining workers about best practice and skill. A manufacturing process that requires inputs from multiple materials and minds lends itself to seeing production as a process of collaboration. The paradox here is that although 'skilled practice' can be understood as a homogeneous set of characteristics, in the conditions of the reconcentration of different skill sets and training bases in the factory, differentiation in opportunity and differentiation in skill are both evident and contested. This can be seen in the physical components, which collectively create a piece of lace, as well as through the intangible aspects, in terms of protocol and practice. These expose the less harmonious aspects of production, where conflicts over best practice and better operators appear, revealing that the 'local' is connected to wider reaching networks elsewhere. Skill is not uncontested, but is power-ridden, value-laden and scale transcendent.

This article builds on research in cultural and economic geography and suggests the importance of understanding the mutual impacts of micro-process and macro-forces by giving attention to the local. We have argued that the factory, a local setting, is a heterogeneous space with links to different material and 
immaterial lineages, practices and networks. Our work place ethnography clearly revealed both collaborations and disconnections at this most intimate scale ${ }^{109}$, and at the same time, connected these to their causes and effects at wider scales. By including theoretical insights from both within and outside geography, we have highlighted how other disciplines may assist in understanding knowledge, skill, embodiment, collaboration and conflict within particular spaces and at differential scales, offering a nuanced interpretation of work based practices and their relevance to cultural and economic geography. This work has shown that knowledge and skill are not bound within an individual, but are distributed across social actors, material objects and locales. The factory's situation within the distributed-now-concentrated lace trade, an individual worker's relationships to knowledge both within and materialized outside their body, and the interrelationships between workers in collaboration and competition in 'making production', are each necessary to an understanding of the spaces of skilled practices and the ongoing paradoxes in the survival of this contemporary industrial craft production.

\footnotetext{
${ }^{1}$ I.P., Twisthand, interview, (06-06-2013)

${ }^{2}$ M.Patchett, 'The taxidermist's apprentice: stitching together the past and present of a craft practice', Cultural Geographies, published online (2015); C.DeSilvey, J.R.Ryan, and S.Bond, '21 stories', Cultural Geographies, Vol. 21 no. 4, (2014) pp. 657-672; D.Harper, Working Knowledge: skill and community in a small shop, University of California Press (1987); E.0'Connor, 'Embodied knowledge in glassblowing: meaning and the struggle towards proficiency' in C.Shilling (ed.) Embodying Sociology: Retrospect, Progress and Prospect. Oxford: Blackwell (2007)
}

${ }^{3}$ C.Gibson, 'Material Inheritances: How Place, Materiality, and Labor Process Underpin the Pathdependent Evolution of Contemporary Craft Production', Economic Geography, Vol. 92. No.1, (2016) p. 66

${ }^{4}$ L.McDowell, "The lives of others: Body work, the production of difference, and labor geographies,' Economic Geography Vol. 91(2015) p. 1, cited in Gibson (2016)

${ }^{5}$ H.Balthet, 'Geographies of production: Growth regimes in spatial perspective 3 - toward a relational view of economic action and policy' Progress in human geography, Vol 30. No 2 (2006); A.Jones, 'Geographies of production 1: Relationality revisited and the "practice shift" in economic geography', Progress in Human Geography, Vol. 38, no. 4 (2014) pp. 605-615

${ }^{6}$ Gibson, 'Material Inheritances'; C.Carr and C.Gibson, 'Geographies of making: rethinking materials and skills for volatile futures', Progress in Human Geography, Vol. 40, no. 3 (2016) pp. 297-315; A.Jones and J.Murphy, 'Theorizing practices in economic geography; Foundations, challenges, possibilities, Progress in human geography, Vol. 35. No 3 (2010)

7 T.Ingold, The Perception of the Environment: Essays on Livelihood, Dwelling and Skill, London: Taylor and Francis, (2000); T.H.Marchand, Making Knowledge: explorations of the indissoluble relation between minds, bodies, and environment, Chichester: Wiley-Blackwell, (2010)

${ }^{8}$ Grant number: AH/K005952/1

${ }^{9}$ T.Fisher and A.Love, 'Animating Representations of Industrial Heritage part 1', TICCIH Bulletin, 
71, (2016), available at: http://ticcih.org/wp-content/uploads/2016/02/tws712016.pdf; T.Fisher and J.Botticello, Animating representations of industrial heritage part 2, TICCIH Bulletin, 70, (2015), available at: http://ticcih.org/wpcontent/uploads/2015/11/ticcih70pg1and24only.pdf; T.Fisher, N.Donovan, and J.Botticello, 'Using 3D Animation to Capture and Preserve Intangible Heritage: Industrial Textile Crafts', Furnace Journal of Ironbridge Industrial Institute for Cultural Heritage, Vol. 3, ISSN 207-519x (2016) https://furnacejournal.files.wordpress.com/2016/03/fisher-donovan-botticello-furnacearticle4.pdf

${ }^{10}$ J.Lave and E.Wenger, Situated Learning: Legitimate Peripheral Participation, Cambridge: Cambridge University Press, (1993)

${ }^{11}$ S.Reimer, 'Geographies of production II: fashion, creativity and fragmented labour', Progress in human geography, Vol. 33. No 1, (2009) p. 65; C.Hadjmichalis and R.Hudson, 'Networks, regional development and democratic control', International journal of urban and regional research, Vol. 30 (2006) pp. 868-9

12 c.f. Gibson, 'Material Inheritances', p. 74 on boot production in El Paso, Texas and its shift to China and Mexico

${ }^{13}$ http://www.clunylace.com/page0004v01.htm, accessed 28-08-2016

${ }^{14}$ http://www.clunylace.com/page0002v01.htm, accessed 28-08-2016

15 J.Botticello, Fieldnotes, (10-05-2013)

${ }^{16}$ Gibson, 'Material Inheritances', p. 77

${ }^{17}$ J.Botticello, 'From documentation to dialogue: Exploring new "routes to knowledge" through digital image making' Visual Studies, Vol. 31, No. 4 (2016)

18 Y.Evans and A.Smith 'Surviving at the margins? Deindustrialization, the creative industries and upgrading in London's garment sector', Environment and planning A, Vol. 38 (2006) p. 2254; S.Reimer, 'Geographies of production II: fashion, creativity and fragmented labour', Progress in human geography, Vol. 33, no. 1 (2009) p. 67; Gibson, 'Material Inheritances', p. 80

${ }^{19}$ For a comparative work based ethnography see J.Botticello, 'Between objectification, classification and perception: Processing secondhand clothes for reuse', Textile, The Journal of Cloth and Culture, Vol. 10, No. 2 (2012) pp. 164-183

${ }^{20}$ Gibson, 'Material Inheritances', p. 68

${ }^{21}$ Marchand, 'Making Knowledge', p.15

${ }^{22}$ A.Jones, 'Geographies of production I', pp. 611

${ }^{23}$ T.Ingold, 'That's enough about ethnography!' Hau: Journal of Ethnographic Theory, Vol. 4. no. 1, (2014): p. 389

${ }^{24}$ Fisher, Donovan, and Botticello, 'Using 3D Animation to Capture and Preserve Intangible Heritage'

${ }^{25}$ Gibson, 'Material Inheritances', p. 82

${ }^{26}$ S.Terkel, Working: people talk about what they do all day and how they feel about what they do, New York: Ballantine Books (1972)

${ }^{27}$ H.Beynon, Working for Ford, London: Penguin (1973) 
${ }^{28}$ M.Glucksman (aka R.Cavendish), Women on the Line, London: Routledge (1982)

${ }^{29}$ Jones and Murphy, 'Theorizing practices in economic geography', p. 367

${ }^{30}$ H.Braverman, Labor and Monopoly Capital: the degradation of work in the twentieth century, New York: Monthly Review Press, (1998) p. 90.

${ }^{31}$ R.Samuel, 'Workshop of the World: Steam power and hand technology in mid-Victorian Britain', History Workshop Journal, 3, 1 (1977), pp. 6-72

${ }^{32}$ Gibson, 'Material Inheritances', p. 61

33 T.Ingold, Being Alive: essays on movement, knowledge and description, Abingdon: Routledge, (2011) pp. 61-62

${ }^{34}$ Jones and Murphy, 'Theorizing practices in economic geography', p. 375

${ }^{35}$ N.Schlanger, 'The chaîne opératoire' in C.Renfew and P.Bahn (eds.) Archaeology: the key concepts, London: Routledge, (2005) p. 27

36 T.Ingold, 'Walking the plank: Mediations on a process of skill', in J. Dakers (ed.) Defining Technological Literacy: Towards an Epistemological Framework, New York: Palgrave Macmillan (2006) p. 79

37 Jones, 'Geographies of production I'

38 J.Lave, Cognition in practice, Cambridge: Cambridge University press (1988) p.1; S.L.Star, 'Working Together: Symbolic Interactionism, Activity Theory and Information Systems', in Y.Engstrom and D.Middleton (eds.) Cognition and Communication at Work, (1996), pp. 296-318

${ }^{39}$ Star, 'Working Together', p. 297

40 Gibson, 'Material Inheritances', p. 64

${ }^{41}$ A.Herod, A.Rainnie and S.McGrath-Champ, 'Working space: why incorporating the geographical is central to theorizing work and employment practices', Work, Employment and Society, Vol. 21, no. 2 (2007) p. 256

${ }^{42}$ Herod, Rainnie and McGrath-Champ, 'Working space', p. 257

${ }^{43}$ Herod, Rainnie and McGrath-Champ, 'Working space', p. 256-9

${ }^{44}$ Botticello, Fieldnotes, documenting I.P. as he describes Cluny Lace, (15-05-2013)

45 D.Lyon and L.Back, 'Fishmongers in a global economy; Craft and social relations on a London market', Sociologocial research online, Vol.17, no. 2, (2012) p. 6

46 The firm did not completely sell off its Raschel machinery until 2005 as it continued to operate a Raschel business on another site, called Manors, elsewhere in Ilkeston.

47 Botticello, Fieldnotes, (08-08-2013)

${ }^{48}$ Botticello, Fieldnotes, (25-04-2013), (24-05-2013)

49 J.S., Brass winder, Interview, (09-05-2013) 
${ }^{50}$ Carr and Gibson, 'Geographies of making'

51 Jones and Murphy, 'Theorizing practices in economic geography', p. 377-8

52 Gibson, 'Material Inheritances', p. 67

53 Jones, 'Geographies of production I', p. 611

${ }^{54}$ Herod, Rainnie, and McGrath-Champ, (2007) p. 258

${ }^{55}$ Botticello, Fieldnotes, (24-05-2013)

56 Gibson, 'Material Inheritances', p. 73

57 W.Felkin, A History of the Machine Wrought Hosiery and Lace Manufactures, London: Longmans Green and Co. (1867); S.Mason, Nottingham Lace, 1760s-1950s: The Machine-made Lace Industry in Nottinghamshire, Derbyshire and Leicestershire, Stroud: Sutton Publishing Ltd. (1994)

58 D.E.Varley, A History of the Midland counties Lace Manufacturers' Association, 1915-1958, Long Eaton: Lace Productions, Ltd (1959 (1948])

59 P.Sharpe and S.Chapman, 'Women's Employment and Industrial Organisation: Commercial Lace Embroidery in Early Nineteenth Century Ireland and England, Women's History Review, Vol. 5, no. 3, (1996) pp. 325-351

${ }^{60}$ A.Gell, Art and Agency, an anthropological theory, Oxford: Claredon Press, (1998)

61 R.Sennett, The Craftsman, London: Allen Lane, (2008) p. 9

62 G.Ryle, The Concept of Mind, Oxford: Routledge, (2009 [1949])

63 Ingold, The Perception of the Environment

${ }^{64}$ D.Schon, The reflective practitioner, how professionals think in action, Aldershot: Ashgate Publishing Ltd. (1991)

65 M.Martinón-Torres, 'Chaîne Opératoire: The concept and its applications within the study of Technology', Gallaecia, Vol. 21 (2002), pp. 29-43; Schlanger, 'The chaîne opératoire'

${ }^{66}$ Ingold, The Perception of the Environment, p. 292

${ }^{67}$ F.M., Warper, interview (02-07-2013)

${ }^{68}$ Botticello, Fieldnotes, (22-05-2013)

${ }^{69}$ Schon, The reflective practitioner

70 I.P., interview, (02-07-2013)

71 P.S., Twisthand, interview, (02-07-2013)

72 L.Malafouris, 'The Cognitive Basis of Material Engagement: Where Brain, Body and Culture Conflate', in E.DeMarrais, C.Gosden, and C.Renfrew (eds.) Rethinking Materiality: The engagement of mind with the material world, Cambridge: McDonald Institute for Archaeological Research, (2004) p. 60

73 P.S., interview, (02-07-2013)

${ }^{74}$ Schon, The reflective practitioner 
75 L.Malafouris, How Things Shape the Mind: a Theory of Material Engagement, Cambridge Massachusetts: MIT Press, (2013) p. 81

${ }^{76}$ Botticello, Fieldnotes (15-05-2013)

77 O’Connor, 'Embodied knowledge', pp. 183-204

78 B.Anderson and D.Tolia-Kelly, 'Matter(s) in social and cultural geography' Geoforum, vol. 35 (2004) p. 669

${ }^{79}$ Jones and Murphy, 'Theorizing practices in economic geography', p. 371

80 Gell, Art and Agency

81 D.Norman, The Psychology of Everyday Things, Basic Books, (1988); D.Norman, 'Cognitive Artefacts', in J.M.Carroll (ed.) Designing Interaction: Psychology at the Human-Computer Interface, Cambridge: Cambridge University Press, (1991); D.Norman, 'Cognition in the Head and in the World', Cognitive Science, Vol. 17, no. 1 (1993) pp. 1-6

82 Marchand, 'Making Knowledge', p. 15

${ }^{83}$ Jones, 'Geographies of production I', p. 611

${ }^{84}$ Lyon and Back, 'Fishmongers in a global economy', p. 9

85 J.S., interview, (09-50-2013)

${ }^{86}$ J.S., interview, (26-03-2013)

${ }^{87}$ J.S., interview, (26-03-2013)

${ }^{88}$ C.Mason, personal communication, (10-08-2015)

${ }^{89}$ F.G., interview, (02-07-2013)

${ }^{90}$ J.S., interview, (09-05-2013)

91 J.Gough, Work, locality and the rhythms of capital. London: Continuum. (2003), p. 3, cited in Gibson, 'Material Inheritances', p. 66

92 I.P., interview, (02-07-2013)

${ }^{93}$ Botticello, Fieldnotes, (07-02-2013)

${ }^{94}$ Reimer, 'Geographies of production II', p. 67

95 Reimer, 'Geographies of production II', p. 67

96 Gibson, 'Material Inheritances', p. 77

97 D.G., Foreman interview, (28-06-2013)

98 Botticello, Fieldnotes, (09-05-2013)

99 J.Ellis, OBE, personal communication, (02-07-2013)

100 Schlanger, 'The chaîne opératoire', p. 27 
${ }^{101}$ Botticello, Fieldnotes, (02-07-2013)

102 Botticello, Fieldnotes (12-04-2013)

${ }^{103}$ Star 'Working Together', p. 299

${ }^{104}$ Balthet, 'Geographies of production', p. 230; Jones, 'Geographies of production I', p. 607

105 Gibson, 'Material Inheritances', p. 65

${ }^{106}$ Malafouris, 'The Cognitive Basis of Material Engagement', p. 60

107 Jones and Murphy, 'Theorizing practices in economic geography', p. 375

108 Gibson, 'Material Inheritances', p. 66

${ }^{109}$ Malafouris, How Things Shape the Mind, pp. 80-1 